\title{
WestVirginiaUniversity
}

THE RESEARCH REPOSITORY @ WVU

West Virginia Agricultural and Forestry Experiment

Davis College of Agriculture, Natural Resources

Station Bulletins

And Design

$1-1-1956$

\section{Pricing piece chicken for kept-up displays}

Norman Nybroten

Follow this and additional works at: https://researchrepository.wvu.edu/ wv_agricultural_and_forestry_experiment_station_bulletins

\section{Digital Commons Citation}

Nybroten, Norman, "Pricing piece chicken for kept-up displays" (1956). West Virginia Agricultural and Forestry Experiment Station Bulletins. 385 .

https://researchrepository.wvu.edu/wv_agricultural_and_forestry_experiment_station_bulletins/375

This Bulletin is brought to you for free and open access by the Davis College of Agriculture, Natural Resources And Design at The Research Repository @ WVU. It has been accepted for inclusion in West Virginia Agricultural and Forestry Experiment Station Bulletins by an authorized administrator of The Research Repository @ WVU. For more information, please contact ian.harmon@mail.wvu.edu. 

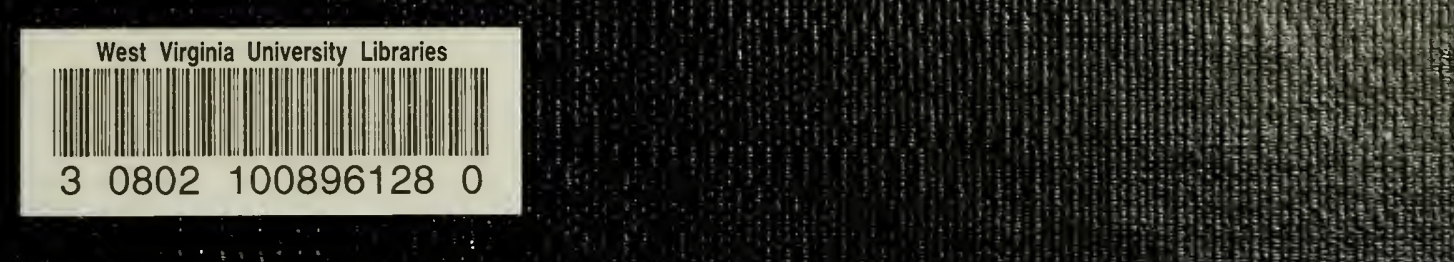
Digitized by the Internet Archive in 2010 with funding from

Lyrasis Members and Sloan Foundation 


\section{BULLETIN 385}

January 1956

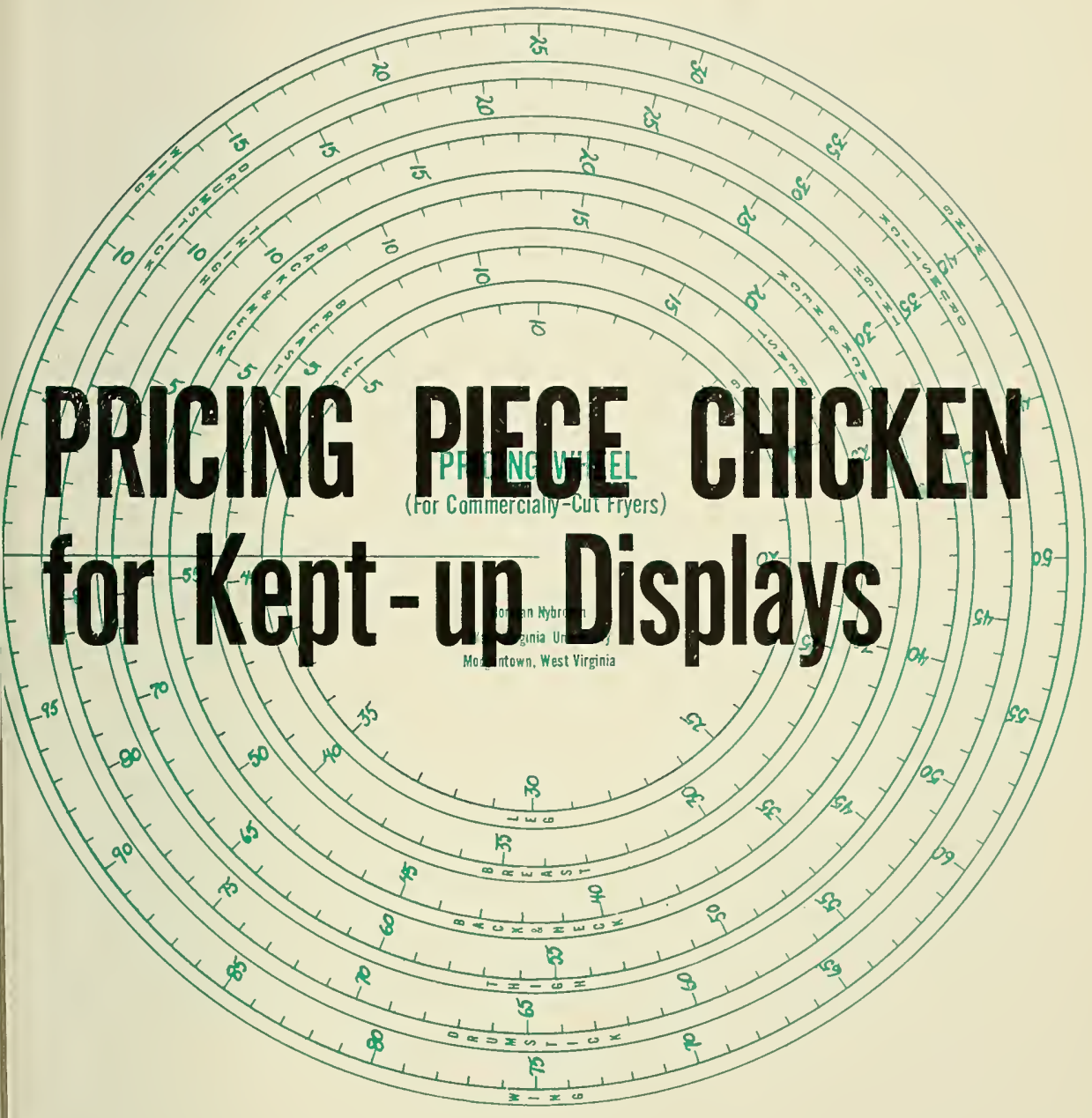

WEST VIRGINA UNIVERSITY AGRICULTURAL EXPERIMENT STATION 
WEST Virginia UNIVERSITY

Agricultural EXPERIMENT STATION

College of Agriculture, Forestry, and Home Economics

H. R. VARNEY, Director

MORGANTOWN 


\section{Summary and Conclusions}

OEVERAL West Virginia studies have indicated that retail displays of poultry meat-especially those of fryer parts-usually are not well kept up. Ideally, displays should be kept up to the point where each part of the fryer is always available, but this presents a task that is seldom accomplished. This problem is more intensive for stores that cut out their own piece chicken in the store than it is for stores that order piece chicken.

Logically, sales of poultry meat are reduced below what could be sold if the customer's choice were available. It is apparent that inflexible prices of different fryer parts contribute greatly to the problem of illkept displays. In order to sell the greatest amount of fryer parts, the local retailer must have one of two freedoms so that he can respond to shifts in demand. He must either be allowed freedom in pricing individual fryer parts in relation to current conditions, or he must be allowed to vary the relative supplies of the fryer parts.

A "PRICING WHEEL" has been developed to provide a means for making flexible pricing which would respond to the local variations as well as variations that result from weather changes. The PRICING WHEEL simplifies the problem of maintaining a stipulated overall price for fryer parts while allowing the prices for individual parts to vary. This device is simple to use and very little instruction would be needed. It can be constructed quite easily after the cut-out percentages for the different fryer parts are known. Limited numbers of these can be obtained free of charge from the West Virginia University Agricultural Experiment Station, Morgantown, W. Va. (State whether fryers are to be cut by the home-style or commercial method.) 


\section{THE AUTHOR}

Norman Nybroten is Agricultural Economist at the West Virginia University Agricultural Experiment Station and Professor of Agricultural Economics in the College of Agriculture, Forestry, and Home Economics.

\section{ACKNOWLEDGEMENTS}

Much of the work reported in this bulletin was in support of the regional project "NEM11, A Determination of the Factors Affecting Consumer Acceptance, Cost and Prices of Poultry Products in the Northeast," and was made possible by funds from the Research and Marketing Act of 1946.

Many retail food stores and organizations helped make the studies possible. Of especial help were Country Produce Company (poultry slaughter plant), Kroger Company, and Evans Grocery Company. Mr. Alvin Kessler, meat manager of the Charleston branch of the Kroger Company and Mr. R. G. Greene, meat manager of the Evans Grocery Company of Gallipolis, Ohio, helped expedite experimental work in meat departments under their supervision.

\section{FRR.1T.1}

1. The paragraph immediately under Table 3 on page 12) should read as lollows:

Assume that the prices are set as in the last column in Table 3 and there is a 1 un on drumstick and a back-up n:s back and neck. Suppose the frumstick price is raised from 80 cents to $\$ 1.00$ per pound. Thus the wheel shown in Figure 2 would be rotated to 20 on "drumstick" because 20 needs 10 be added to 80 . "It this position of the wheel the reading for back and neck is 10 cents and it is immediatel! known that reducing back and neck 10 cents and increasing drumstich 20 cents will not (hange the average price receised for the drawn bird. To obtain aterages of $1.5,55$, (30) or 70 cents the procedure is the same as that given lor Table?.

II. In ligure "2 on page t3 the itcm "Breast" should be interchanged with "Bach and Nech." 


\section{Pricing Piece Chicken for Kept-up Displays}

\section{Introduction}

NORMAN NYBROTEN

ETAIL meat departments began to change over to a self-service basis during recent years. Some stores are self-service on whole chicken but do not have piece chicken available at self-service. The selfservice meat counter has been a boon to the poultry meat industry, especially in sales of piece chicken (chicken parts). Chicken sales have increased, although not solely from this, along with the self-service trend in meat. Some of the store managers in West Virginia believe that selfservice has increased their poultry meat sales by several times. This view is held despite the fact that in the summer of 1952 less than onethird of the homemakers in a West Virginia study expressed a preference for complete self-service on poultry meat.

Although modern self-service merchandising of chicken meat has helped sales, it could help more. Anyone going to the display of piece chicken on a Saturday afternoon is likely to see a sight not pleasing to the eye. It is quite typical to see only a few of the fryer parts in the display. This is by no means confined to Saturday afternoon but is more likely to happen immediately before a holiday-especially a double holiday. The reason is, of course, that the retailer failed to estimate his sales correctly and tried to avoid carry-over.

Several unreported studies of different kinds have been made of retail poultry meat displays in West Virginia. All of these studies, involving several seasons and more than fifty stores under five different chains and under independent managements, indicate one common result. Poultry meat sales are not as great as they might be because the shopper frequently does not find what she wants. The principal cause of this is the fixed price relationships set by central chain management. Independents are also prone to follow these.

\section{Some Results of Display Studies}

In one large chain supermarket the fryer-parts display was observed in great detail for a seven-week period. This store received only whole fryers and cut them up for piece chicken. Prices for each chicken part were fixed in a branch office of the chain organization. 
In this study careful inventories were taken to study the volume of sales of different parts of the fryer while they were in competition under different price relationships. In addition to daily opening and closing inventories of the display, inventories were taken the instant a part was entirely exhausted from the display as well as when there was any price change. The main results of this study were negative. It was learned that it does not seem feasible to try to develop a formula for pricing fryer parts at a central point and expect to sell predicted relative amounts of the different parts. In order to respond to variations in demand, it is necessary for the local retailer either to have freedom to adjust relative prices of the parts or adjust the relative supply of the parts.

From this study, the main thing of interest for this report is the prevalence of different parts of fryer in the display during the 499 store hours of the study. These results are shown in Table 1. It is evident that the different parts were not priced to sell in relation to the proportionate yield from the bird because three of the items were available to customers less than half of the time. In fact, the edible viscera were available less than one-third of the time compared with legs being available nearly full-time (96 per cent). Clearly, the viscera were relatively underpriced on the local market compared with legs. If the different parts had been priced correctly in relation to the fixed relative supplies (cut-out yields), they would all have sold out in approximately the same amount of time.

In another study, 1,732 visits were made to poultry meat displays in 32 West Virginia supermarkets from August, 1954, to June, 1955. These were semi-weekly and the time of each visit was not known to the store pcrsonnel. The fryer part most frequently found by the visiting observer was breast, which was available 76 per cent of the time on the average for all of the stores. Eleven of these stores bought fryer parts from the slaughter plant, and the other 21 cut out all the piece chicken in the store. From the standpoint of the variety available to customers, the

Table 1. Portion of the Time Different fryer Parts Were Avallable in a Large Self-Servige Supermarket During a Total of 499 Storf.

Hours

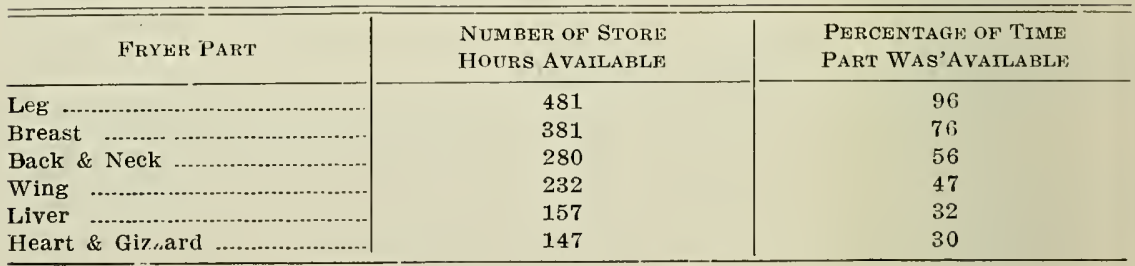


are most wanted. ${ }^{1}$ The costs involved in this system compared with cutting out piece chicken in the store need to be studied before a definite recommendation can be made as to where in the marketing channels piece chicken can most economically be cut out.

In an experiment in one of the larger supermarkets the author had the privilege of setting the prices of fryers and fryer parts. Although this experiment has not been completed, it is quite evident that sales of fryer parts can be increased significantly by giving the store's meat department flexibility in pricing so that geographic and short-time changes in demand can be considered.

If prices are to be adjusted to differences in demand among small geographic areas and for short-time variations in demand, some of the advantages of mass advertising by chains may be lost. Although this might be somewhat of a handicap, it is not as great as might be surmised. A study of weekly food-store advertising shows that it is usually the fryer as a whole (meaning drawn or cut up with all parts in a package) that is featured in the advertising.

Several thousand homemakers in the major cities of West Virginia have been interviewed to learn their preferences for poultry meat. Principle results of this study are to be reported elsewhere, but it was learned that preferences varied by locality. These localities are not conterminous with pricing "districts" of chain stores.

Another thing of importance learned in the study of within-store pricing was that relative pricing of fryer parts presents a mathematical problem. The store management, chain or otherwise, is interested in maintaining a certain mark-up. This, since the parts have different weights, entails a weighted average--which is usually cumbersome to people not trained in mathematics or statistics. It is essentially for this reason that chain-store managements do not entrust this type of pricing to personnel in local stores. In this study, several types of aids in the arithmetic of relative pricing of parts were used. A simple device that will be called the "Pricing Wheel" was developed."

1Cutting out and distributing piece chicken at a central point does not, of course, entirely the the problem of pricing fryer parts relatively-that is, one part in relation to another. It does, however, make the supply problem much easier for the local retailer. The total demand for the different parts of fryers is more predictable for a large geographic area than for a small one-giving advantage to central-point cutting. It is also more efficient to watch for runs and back-ups at a central point because the volume would be much larger than at the local store. The central point has the disadvantage of more time lag in the adjustments of the prices to the demand.

2To state that the pricing wheel was "developed" may possibly be misleading because it is somewhat like a circular slide rule. It was, however, adapted to this particular pricing problem and it might be pointed out that it could very well be a simple aid in pricing other products where the weights of the different products or by-products have a fixed relationship to the weight of the source product. It could, of course, be used to price meat cuts from animals other than fryers, or it might be constructed for only parts of a section of an animaI. 


\section{Using the Pricing Wheel}

The influence of a particular part of a fryer on the average price realized for the drawn bird is determined by the relative weight of the parts and the price. This complicates the pricing of parts because it must be done on the basis of a "weighted" average. Perhaps the way this works can be made clear by thinking of children on a seesaw. The lighter child offsets his lack of weight by getting out farther and swings in a wider arc. It is the same way with fryer parts-the price of lighter parts must change more than those of the heavier parts, if the up-and-down changes are to offset each other. In fact, the price changes will be inversely related to the weights. The pricing wheel has been constructed on this principle.

By relative weight of a fryer part is meant the percentage its weight is of the weight of the drawn bird. This will, of course, vary somewhat among individual birds, but the average for large numbers of birds will be quite stable unless birds have been bred up for abnormal conformation.

There are two main methods of cutting fryers. The "home-cut" method leaves the ribs and the oysters on the back. The "commercial" method leaves the ribs in with the breast and the oysters in with the thighs. The part of the wing meat covering the humerus bone is often cut as part of the breast. The commercial method maximizes the amount of meat on the more valuable parts and minimizes the amount on the less valuable. In the West Virginia markets, fryers are nearly always cut by the home-cut method if all the different parts are to be sold in one package. If the different parts are to be priced and sold separately, the commercial method is used to some extent, but the home-cut method is by far the more common even for this purpose.

The prices in Table 2 are based on cutting experiments in a large food market. The method of cutting was nearly all commercial-the only exceptions being that about half of the oyster was left on the back

\section{Table 2. Base Prices for Commercial Cuts of Chicken Fryer}

\begin{tabular}{|c|c|c|c|}
\hline \multirow{2}{*}{$\begin{array}{l}\text { COMMERCIAL CUT } \\
\text { OF CHICKEN FRYER }\end{array}$} & \multirow{2}{*}{$\begin{array}{c}\text { PERCENTAGE } \\
\text { WEIGH'T ls OF } \\
\text { DRAWN BIRD }\end{array}$} & \multicolumn{2}{|c|}{ Base Price That Will Return: } \\
\hline & & $\begin{array}{l}\text { 50 Cents Per POUnd } \\
\text { FOR DRAWN Bird }\end{array}$ & $\begin{array}{c}65 \text { Cents Per Pound } \\
\text { Hor Drawn Bird }\end{array}$ \\
\hline Breast ….................. & 27.2 & $\$ 0.75$ & $\$ 0.95$ \\
\hline Back \& Neck ............. & 22.3 & .10 & .20 \\
\hline Thigh .......................... & 16.8 & .70 & .85 \\
\hline Drumstick ................ & 14.4 & .60 & .80 \\
\hline Wing ……...................... & 12.4 & .20 & .30 \\
\hline Heart \& Gizzard ..... & 3.9 & .40 & .50 \\
\hline 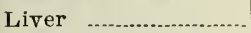 & 3.0 & .95 & 1.10 \\
\hline Total & 100.0 & .50 (Av.) & .65 (Av.) \\
\hline
\end{tabular}


and most of the meat covering the humerus bone was cut with the wing. The cut-out percentages are based on allowing a very small loss for cutting, trimming and any other factor reducing the weight below what the total would have been had the fryer been sold as a drawn bird. The breed of bird was New Hampshire.

Two sets of "base" prices are shown in Table 2. One set is calculated to give a return of 50 cents per pound for the drawn bird and the other 65 cents. These prices should not be interpreted as ideal relative prices but merely as bases from which to calculate. If the meat department in a store were to price piece chicken and had no previous experience, the prices in Table 2 would probably be as good as any but should be thought of merely as tentative beginning prices.

Assume that a store cuts up its own piece chicken on a basis near the commercial-cut method. Also assume that it is desired to average 65 cents per pound for the drawn bird and the several parts are trial priced as in the last column in Table 2. If there is a "run" on any one part, it means it is underpriced, whereas if it "backs up"-that is, the supply of it accumulates in the store-it is overpriced. If, for example, there is a run on wings at the 30 -cent price and breast is backing up at the price of $\$ 0.95$, then the problem is to increase the price of wing and decrease the price of breast. Suppose wing is to be priced at 50 cents. This would mean that the pricing wheel for commercially-cut fryers shown in Figure 1 would be turned to the point where the circle marked wing gives a reading of 20 along the stretched string or wire20 because it is to be increased from 30 to 50 . At this position the reading on the circle for breast is 9 . This means that in order to realize the same average price for the piece chicken, the price of breast should be decreased to 86 cents to offset having increased wing to 50 cents. Because the readings need to be rounded to the nearest whole cent there is a small rounding error--such as on ordinary weighing scales. In the instance at hand, a 20-cent-per-pound increase on wing amounts to $\$ 0.20 \times .124 \times 1000=\$ 24.80$ per thousand pounds of piece chicken sold. The 9-cent-per-pound reduction on breast amounts to $\$ 0.09 \times .272$ x $1000=\$ 24.48$ per thousand pounds of piece chicken. The .124 is used because wing is 12.4 per cent of the total and the .272 because breast is 27.2 per cent of the total. Actually the increase and reduction came within $\$ 0.32$ of offsetting each other on $\$ 650$ worth of piece chicken (1000 pounds at 65 cents per pound). In the long run these errors would offset each other because they would have a 50-50 chance to be short one time and long another time.

Suppose the retailer wants to average 60 cents per pound for the drawn bird. He would then subtract 5 cents from each of the part 


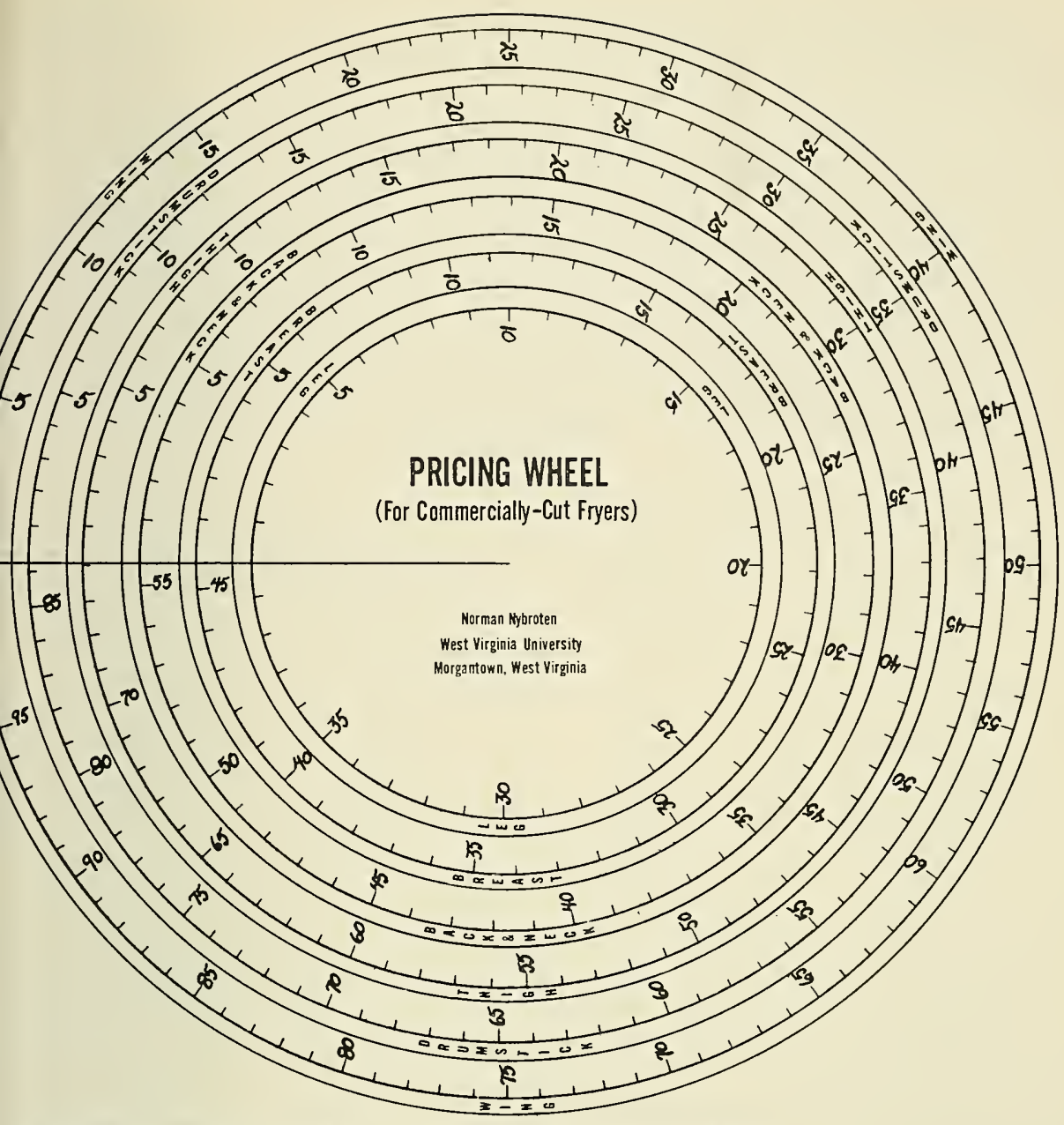

FIGURE 1. Pricing Wheel for commercially-cut fryer parts.

prices shown in the last column of Table 2 and use these for the beginning trial prices. After having set the "trial prices" the next step is to watch for runs and back-ups. If these develop, the procedure is the same as for the 65-cent price above because the Pricing Wheel gives only changes needed and does not set a level of prices. This column would also be used for a 70-cent average by adding 5 cents to each part price. The nextlast column in the table could be used for a 45-, 50-, or 55-cent average.

Table 2 treats liver as a chicken part and heart and gizzard as a separate item. Either of these represents only a small percentage of the drawn bird and a price change in it will have a relatively small effect on the average price for the drawn bird. If the retailer wants to use the 
Pricing Wheel on these parts, it is possible to do so with a practicable degree of accuracy. Use the "wing" circle for either of them and multiply the reading by 3 for gizzard and heart and by 4 for liver.

Table 3 is included to give base prices for fryer parts cut out on the home-cut method. In this method, both the breast and the back would ordinarily be more valuable per pound than if cut out by the commercial method. It would also be necessary to get more per pound for these parts in order to realize a certain average. If we assume a store is using the home-cut method and wants to average 65 cents a pound for the drawn bird, the prices in the last column in Table 3 may be used as the beginning "trial prices." When these have been set, the display needs to be watched for runs and back-ups.

Table 3. Base Prices for Home-Style-Cut Fryer Chicken

\begin{tabular}{|c|c|c|c|}
\hline \multirow{2}{*}{$\begin{array}{c}\text { CUT OF THE } \\
\text { CHICKEN FRYER }\end{array}$} & \multirow{2}{*}{$\begin{array}{l}\text { Percentage } \\
\text { Weight Is OF } \\
\text { Drawn BIRD }\end{array}$} & \multicolumn{2}{|c|}{ Base Price That Will Returi: } \\
\hline & & $\begin{array}{l}50 \text { Cents PER POUNd } \\
\text { FOR DRAWN BIRd }\end{array}$ & $\begin{array}{l}65 \text { Cents Per Pound } \\
\text { FOR Drawn Bird }\end{array}$ \\
\hline 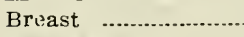 & 20.95 & $\$ .90$ & $\$ 1.10$ \\
\hline Back \& Neck ........... & 29.56 & .21 & .29 \\
\hline Thigh ............................ & 16.19 & .60 & .83 \\
\hline Drumstick & 14.76 & .60 & .80 \\
\hline Wing & 12.48 & .20 & .30 \\
\hline Heart \& Gizzard .... & 3.61 & .40 & .50 \\
\hline Liver & 2.45 & .95 & 1.10 \\
\hline Total & 100.0 & $.50 \quad(\mathrm{Av})$. & .65 (Av.) \\
\hline
\end{tabular}

Assume that the prices are set as in the last column in Table 3 and there is a run on wings and a back-up on backs and neck. Suppose the wing price is raised from 30 cents to 50 cents a pound. Thus the wheel, shown in Figure 2, would be rotated to 20 on "wing" because 20 needs to be added to 30 . At this position of the wheel the reading for back and neck is 10 cents and it is immediately known that reducing back and neck 10 cents and increasing wing 20 cents will not change the average price received for the drawn bird. To obtain averages of $45,55,60$ or 70 cents the procedure is the same as that given for Table 2.

It should be borne in mind that the Pricing Wheel is based on selling poundage of the different chicken parts in proportion to the cut-out yields for the different parts. If a "run" is allowed to continue too long on one part and another part is allowed to "back up," the desired average price will not be realized for the drawn bird because the part that is to be increased in price will have partly "run out" before the price is increased, whereas there will be a relative over-supply of the part to be decreased in price. The only way to overcome this is to set a slightly higher base price for the drawn bird than the desired average price and 


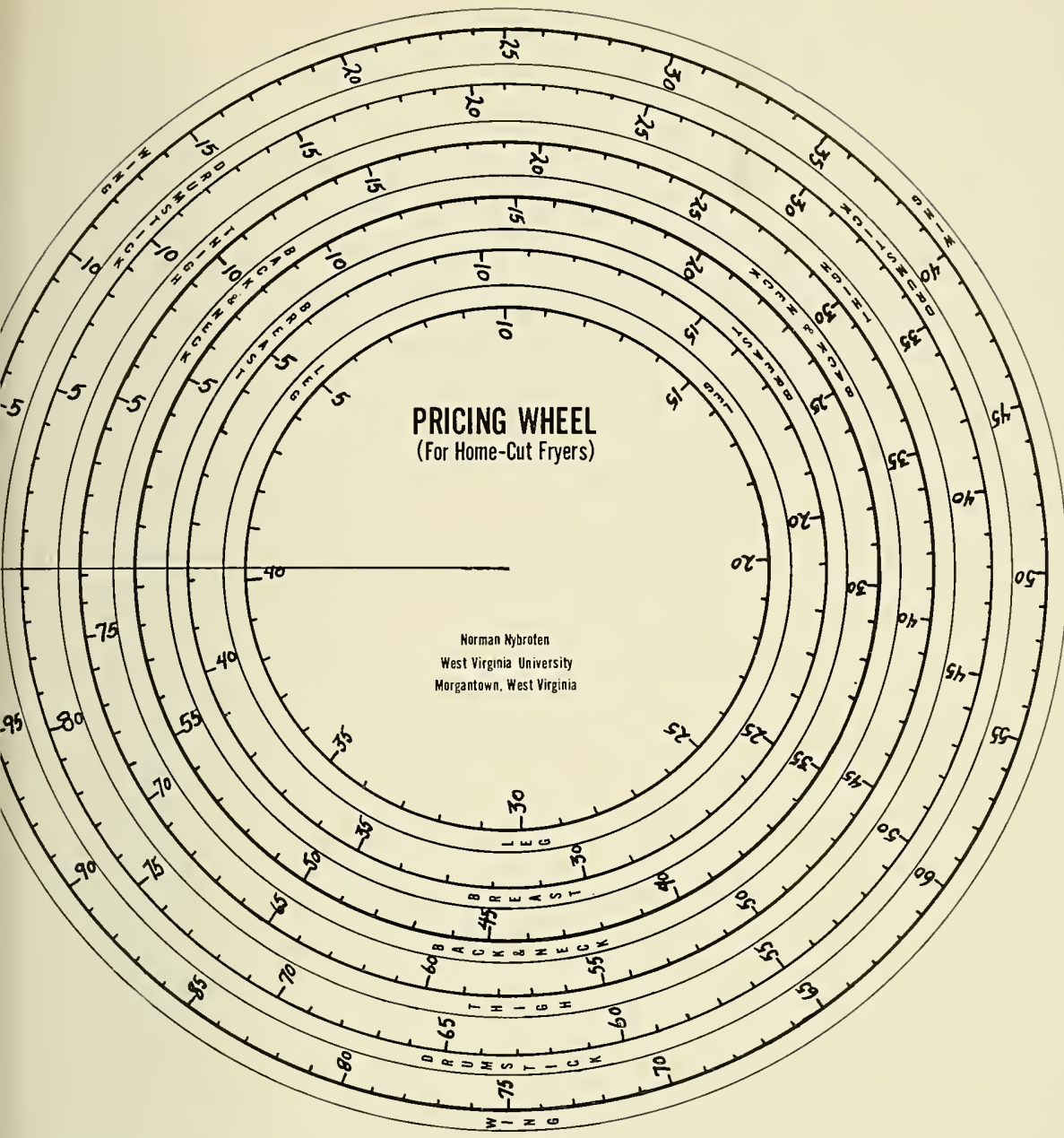

FIGURE 2. Pricing Wheel for home-style-cut fryer parts.

adjust prices for runs and back-ups early. This difficulty must not be thought of as one introduced by the Pricing Wheel. The now common practice of reducing the price of the part that backs up, without a conpensating increase in another part, reduces the average price for the drawn bird even more. Using the Pricing Wheel should go a long way toward remedying this situation. 


